\title{
Trends in delivery with no one present in Nigeria between 2003 and 2013
}

\author{
This article was published in the following Dove Press journal: \\ International Journal of Women's Health \\ 7 April 2015 \\ Number of times this article has been viewed
}

\author{
Anne Austin' \\ Bolaji Fapohunda 2,3 \\ Ana Langer' \\ Nosakhare Orobaton ${ }^{2,3}$ \\ 'Maternal Health Task Force, \\ Harvard TH Chan School of Public \\ Health, Boston, MA, USA; ${ }^{2}$ John \\ Snow, Inc., Boston, MA, USA; ${ }^{3}$ USAID \\ Targeted States High Impact Project, \\ Washington, DC, USA
}

Purpose: Skilled attendance at birth is a proven intervention to improve maternal and newborn health outcomes. Unfortunately, in Nigeria there are many women who give birth alone, with no one present (NOP). The purpose of this study was to document trends in women delivering with NOP between 2003 and 2013, and to identify the characteristics of women who are engaging in this risky practice.

Methods: We utilized pooled data sets from the 2003, 2008, and 2013 Nigerian Demographic and Health Surveys. Married women, who had given birth in the 5 years before each survey were included, resulting in a sample size of 38,949 women. We used logistic regression to assess the unadjusted and adjusted odds of a woman delivering with NOP over time, by sociodemographic characteristics.

Results: Prevalence of delivery with NOP in Nigeria declined by $30 \%$ between 2003 and 2013. The largest declines occurred in Sokoto State, where the number of women giving birth with NOP declined by almost 100\% between 2003 and 2013. In the North West of the country, however, there was a $27 \%$ increase in the number of women giving birth alone over this time period. Older, poorer, less educated, higher parity, Muslim women residing in the Northern regions were significantly more likely to give birth with NOP. Women, who were involved in decisions surrounding their own health, and who had accessed antenatal care were significantly less likely to give birth with NOP.

Conclusion: Although there have been improvements in Nigeria's Maternal Mortality Ratio since 1990, recent estimates suggest a stagnation in this trend. One reason for this protracted decline may be lack of access to skilled delivery care. The 2013 national prevalence of Nigerian women giving birth with NOP was 14\%, equivalent to over 1 million births in 2013. Nigeria must implement interventions to ensure every woman's timely access to, and use of skilled care to reduce preventable maternal mortality and morbidity.

Keywords: skilled birth attendance, delivery with no one present, maternal mortality, facilitybased delivery, health care seeking behaviors, Nigeria

\section{Introduction}

Nigeria is the second largest contributor to the global maternal death toll. Alone, it accounts for $14 \%$ of global maternal deaths, with an estimated 36,698 maternal deaths in 2013. This burden is disproportionate, as Nigeria represents only $2 \%$ of the global population. ${ }^{1,2}$ Although some improvements in the abysmal maternal mortality situation in the country have been recorded over the past 20 years, current estimates released by the Nigerian Demographic and Health Survey (NDHS) indicate that this decline is stagnating with no significant differences between the 2008 and 2013 maternal mortality ratio (MMR) estimates. ${ }^{3}$

One key intervention to improve maternal health outcomes is to ensure that all women have access to skilled care during labor and delivery. ${ }^{4-7}$ Unfortunately, less
Correspondence: Anne Austin Maternal Health Task Force, Harvard TH Chan School of Public Health, 677 Huntington Avenue, Boston, MA 02II5, USA

Tel + I 6175326943

Email amaustin123@gmail.com 
than $40 \%$ of Nigerian women gave birth with a skilled attendant in 2013, and there has been no real change in that proportion over time. ${ }^{3}$ These data suggest that over $60 \%$ of Nigerian women are at excess risk of maternal death, as they do not have access to or utilize available life-saving services. Within this population, there are women who deliver with unskilled companions who could, in the case of an emergency, potentially act as a conduit to the health system where needed services might be available, while they also provide emotional support and comfort to laboring mothers. But there is also a considerable proportion of women giving birth alone with no one present (NOP) who are even more vulnerable as they neither have access to skilled attendance nor do they have the marginal protection and social support supplied by an unskilled birth companion. Fapohunda and Orobaton found that almost $20 \%$ of all women in Nigeria had given birth with NOP in 2008, and the most recent data available show that although there has been a marked improvement in this situation, with a $30 \%$ decline over time, the proportion of women giving birth with NOP is still unacceptably high, $14 \%$ nationally in $2013 .^{3,8}$ According to the most recent NDHS data available, Nigeria is a clear outlier in terms of the proportion and absolute numbers of births with NOP. Only one country, Niger, had a higher percentage of women who gave birth with NOP (2012 estimates of $15.1 \%) .{ }^{9}$ While the percentage of women who give birth with NOP in Niger may be slightly higher, the sheer number of women giving birth with NOP in Nigeria is much larger due to its population base. Based on Nigeria's projected population in 2013 and assuming a $5 \%$ pregnancy rate, there would have been over 1 million women who delivered with NOP in 2013. ${ }^{10}$

This paper analyzes trends in women delivering with NOP and explores factors at the individual, household, and systems levels that may be contributing to this phenomenon in Nigeria. Figure 1 presents a conceptual framework of the individual, household, and systems-level factors that may ultimately inform women's choice, ability, and decision to seek and access to skilled, unskilled, or no attendance at birth. At the systems level, the availability, accessibility, and quality of care are all products of the health system's investment in the infrastructure, human resources, and financing. These investments determine whether or not quality services are available, affordable, accessible, and acceptable to women seeking skilled birth attendance. These systems-level inputs are mediated through a variety of household and individual level factors that ultimately shape whether or not a woman is able to choose and access skilled care. As the geographic distribution of services in Nigeria varies by urban and rural residence and between states, the household's location may directly impact the availability of care. ${ }^{11}$ Additionally, if the health system is unable to provide affordable care, even when care is available, a household's disposable income will determine whether skilled care is accessible to women. In other words, women may live

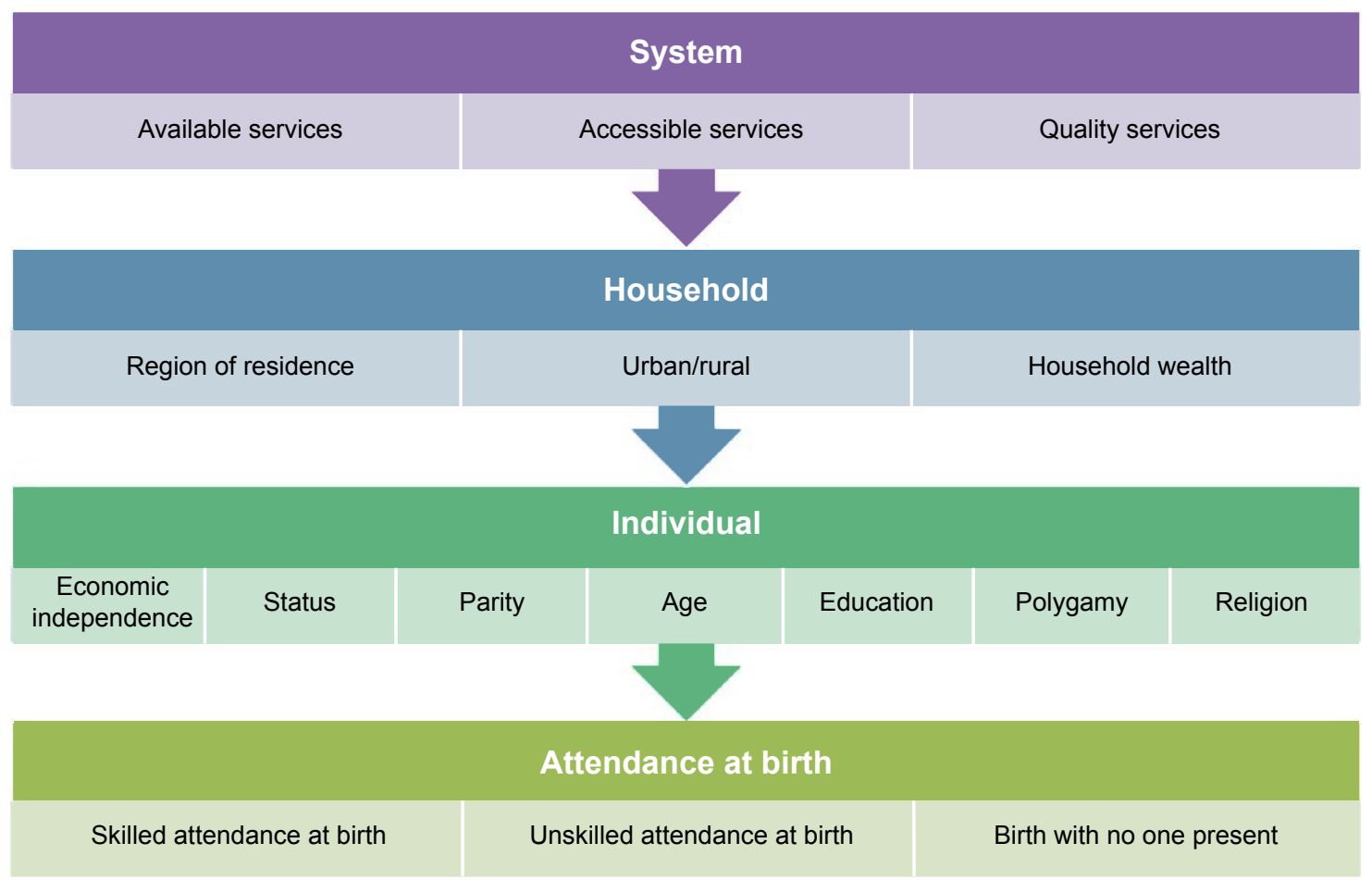

Figure I Conceptual framework of the systemic, household, and individual factors that impact attendance at birth. 
in a context that provides physical access to quality care and reside in a household with the resources to afford care, but factors at the individual level may ultimately determine whether or not she is able to, or chooses to, access this care. Religion has been shown to be a key determinant of health seeking behavior in Nigeria, as has polygamy, women's empowerment, maternal age, education, and parity. ${ }^{12-17}$ It should be noted that although the progression from system to individual factors is depicted as a linear progression in this flowchart, interactions between and within each of these levels are multiple.

Understanding these aspects better, how they have changed over time, and teasing out the relative influence they have on the practice of women giving birth with NOP is critical both for policies and programs. Doing so will allow the identification of potential interventions to mitigate the risks associated with giving birth with NOP and encourage the implementation of measures to increase the number of women accessing skilled care. These changes may, ultimately, lead to a reduction in the number of Nigerian women who die or are injured while giving birth.

\section{Methods}

For these analyses, we pooled the 2003, 2008, and 2013 Nigerian Demographic and Health Survey Data. Analyses were restricted to married women, who had given birth at least once in the 5 years preceding the survey, resulting in a total sample size of 38,546 women. We compared women, over the 3 most recent survey years, whose most recent birth occurred with NOP vs women who had "anyone" present during their most recent birth, regardless of their skill level.

The analyses incorporated explanatory variables, derived from literature, on maternal health care-seeking behavior in Nigeria and is conceptualized in Figure 1. At the systems level, we assessed the availability of care utilizing a variable that assessed the self-reported difficulty women had in accessing care, as well as their contact with maternity services. The indicators are distance to services and the number of antenatal care visits women received during their most recent pregnancy. The proxy indicator for quality of maternal care is the utilization of iron supplements during the most recent pregnancy. Household wealth, urban/rural residence, and region of residence were used to assess household level inputs into care-seeking behavior. At the individual level, we explored the role of age, education, employment status, and parity as predictors of giving birth with NOP. Five additional variables were incorporated to assess women's status and decision making power: polygamy, a woman's employment status, her involvement in making decisions about her own health, her attitudes toward the acceptability of intimate partner violence, and the ease of obtaining husband's permission for facility-based care.

Table 1 presents an overview of how these variables were defined and operationalized in these analyses. As shown, the

Table I Variables used in the analysis

\begin{tabular}{|c|c|}
\hline Variable & Definitions and reference groups (ref) \\
\hline Year & $2013 ; 2003 ; 2008$ (ref) \\
\hline Age (years) & $15-24 ; 25-34 ; 35+($ ref $)$ \\
\hline Total number of live births & $\mathrm{I} ; 2 ; 3 ; 4+($ ref $)$ \\
\hline Urban/rural residence & Urban; rural (ref) \\
\hline Religion & Muslim; Christian/Catholic/Other (ref) \\
\hline Region of residence & North Central; North East; North West; South East; South South; South West (ref) \\
\hline Level of education & Primary, secondary, secondary + , none (ref) \\
\hline Wealth quintile & NDHS wealth quintiles I, poorest; $2 ; 3 ; 4 ; 5$, richest (ref) \\
\hline Employment status & Has worked in 12 months preceding the survey; not currently working (ref) \\
\hline $\begin{array}{l}\text { Attitudes toward intimate physical } \\
\text { partner violence }\end{array}$ & $\begin{array}{l}\text { Intimate partner violence is justified if a wife goes out without telling her husband; wife } \\
\text { neglects her children; wife argues with her husband; a wife refuses to have sex with her } \\
\text { husband or she burns food vs intimate partner violence is not permissible under any of } \\
\text { the above circumstances (ref) }\end{array}$ \\
\hline Women involved in health care decisions & $\begin{array}{l}\text { Respondent is involved in decisions regarding her health, either alone, with a spouse or } \\
\text { with another person; respondent is not involved in decisions regarding her health (ref) }\end{array}$ \\
\hline Number of antenatal care visits in most recent pregnancy & Coded as $0,1,2,3,4,5+$ (used as a continuous predictor variable in the analyses) \\
\hline $\begin{array}{l}\text { Woman bought or was given iron tables or syrup during } \\
\text { their most recent pregnancy }\end{array}$ & Yes; no (ref) \\
\hline $\begin{array}{l}\text { Woman stated that getting permission to seek health care } \\
\text { was a big problem, when getting medical care for herself }\end{array}$ & Yes; no (ref) \\
\hline $\begin{array}{l}\text { Woman stated that the distance to a health facility } \\
\text { was a big problem, when getting medical care for herself }\end{array}$ & Yes; no (ref) \\
\hline Outcome variable & Birth with no one present; birth with any individual present, regardless of skill (ref) \\
\hline
\end{tabular}

Abbreviations: NDHS, Nigerian Demographic and Health Survey; ref, reference group. 
outcome variable grouped attendance by anyone and skilled attendance into the same group. It must be clarified that the authors are not advocating for anything less than skilled birth attendance. The dichotomization of NOP vs "anyone present" was used to identify the most vulnerable of the vulnerable for critical focus.

Unadjusted and adjusted logistic regression procedures were used to assess the association between each of the predictor variables and the outcome of interest. The analyses were conducted using SAS v. 9.2 survey procedures. All analyses were adjusted for survey design and sampling errors. Sample weights were applied to correct for unequal sampling within groups. ${ }^{18}$ This study was granted exempt status by the Harvard School of Health Institutional Review Board.

\section{Results}

\section{Study population}

Table 2 presents the weighted distribution of each of the indicator variables used in this analysis. As shown, almost half of the women were 25-34 years of age, with about one-fourth of the sample in the 15-24 and 35-49 age group, respectively. Fifty-three percent of the women had four or more births, and these estimates appeared to change very little overtime. The vast majority of the women were from rural settings $(67 \%)$; the northern regions, and from poorer households. With respect to the latter, roughly two-thirds of the population was located in the bottom three wealth quintiles; $36 \%$ were not working, $33 \%$ had cowives, and 57\% were Muslims. Almost half of the women (46\%) said they would tolerate intimate physical partner violence, and about two-thirds reported no involvement in decisions regarding their own health. More than half of the women received iron supplements during their most recent pregnancy, and roughly one in ten had four or more ANC visits. Twelve percent of women in 2013 stated that getting permission to seek health care for themselves was a big problem, and almost a third noted that distance was a big problem when trying to access health care (Table 2).

These estimates change very little across the years studied. The exceptions were age and regional compositions, which appeared to indicate that the sample population was older and more Northwestern in 2013 compared to the earlier surveys. Unfortunately, the data suggest that there was a significant increase in the number of women who found distance to be a barrier to accessing care. The data also show positive improvements in some parameters of women's status, ie, there were declines in the number of women who found intimate partner violence acceptable and increases in the number of women who were involved in decisions involving their own health care. The use of logistic regression allowed us to partition these compositional differences so that we are able to truly observe changes in the population behavior during the intersurvey periods.

\section{Unadjusted results}

Figure 2 presents the trends in women who gave birth with NOP in Nigeria, by region. The proportion of women delivering with NOP increased everywhere between 2003 and 2008 but declined over the next 5 years, between 2008 and 2013. During the latter period, prevalence of delivery with NOP declined by $36 \%$ in the North West, $40 \%$ in the North Central, and over 50\% in the North East. Further analysis of state-by-state patterns of change between 2003 and 2013 with data from the 20 states in northern Nigeria where $91 \%$ of NOP were concentrated, revealed that the national and state summaries masked state-specific situations. Ten of the 20 states experienced declines in NOP over the decade, ranging from a high of $99 \%$ in Sokoto and Yobe States, to over $80 \%$ in Kwara and Kogi States, to over $70 \%$ in Federal Capital Territory - Abuja, to a low of $20 \%$ in Bauchi State. At the same time, NOP prevalence rose in 10 states during the same period, reducing the overall size of the decline (Table 3).

Table 4 presents the bivariate estimates of the odds of NOP delivery between 2003, 2008, and 2013. Women were 30\% and 54\% more likely to deliver with NOP in 2003 and 2008, respectively, compared with 2013. Overall, women residing in the North, and particularly, the North West disproportionately bore the burden of delivery with NOP. Older, rural women with higher parity were significantly more likely to give birth alone, relative to younger, urban women, with fewer children. There was a clear wealth and education gradient apparent in the unadjusted analysis, with poorer, less educated women being significantly more likely to deliver with NOP, when compared to women in the wealthiest quintile, who also had higher educational levels. Muslims were four times as likely to give birth alone, unadjusted $\mathrm{OR}=4.36$; (3.73-5.09), when compared to women from other faiths. Employed women were significantly less likely to give birth alone, relative to unemployed women, unadjusted $\mathrm{OR}=0.70 ;(0.64-0.78)$, as were women who were involved in making decisions about their own health, unadjusted $\mathrm{OR}=0.28 ;(0.25-0.32)$. Women, who were cowives, $\mathrm{OR}=2.13 ;(1.96-2.31)$, and who justified intimate partner violence $\mathrm{OR}=1.40 ;(1.26-1.57)$ were significantly more likely to give birth alone, relative to women in monogamous marriages who believed there was no justification for intimate partner violence. 
Table 2 Weighted distribution of the analysis variables, by survey year, among married Nigerian women who had given birth in the 5 years preceding the survey

\begin{tabular}{|c|c|c|c|c|}
\hline Variable & $2003(\%)$ & $2008(\%)$ & $2013(\%)$ & $x^{2}$ \\
\hline \multicolumn{5}{|l|}{ Gave birth alone (most recent birth) } \\
\hline Yes & 17.55 & 20.11 & 14.04 & \multirow[t]{2}{*}{$<0.0001$} \\
\hline No & 82.45 & 79.89 & 85.96 & \\
\hline \multicolumn{5}{|l|}{ Age (years) } \\
\hline $15-24$ & 29.38 & 24.42 & 24.64 & \multirow[t]{3}{*}{0.0001} \\
\hline $25-34$ & 45.93 & 47.88 & 47.69 & \\
\hline $35+$ & 24.70 & 27.70 & 27.67 & \\
\hline \multicolumn{5}{|l|}{ Number of births } \\
\hline 1 & 17.77 & 15.32 & 15.82 & \multirow{4}{*}{0.0093} \\
\hline 2 & 14.68 & 16.55 & 16.40 & \\
\hline 3 & 13.75 & 15.77 & 15.23 & \\
\hline $4+$ & 53.81 & 52.36 & 52.55 & \\
\hline \multicolumn{5}{|l|}{ Cowife ${ }^{a}$} \\
\hline Yes & 34.90 & 32.26 & 32.72 & \multirow[t]{2}{*}{0.3538} \\
\hline No & 65.10 & 67.74 & 67.28 & \\
\hline \multicolumn{5}{|l|}{ Residence } \\
\hline Urban & 28.20 & 30.19 & 34.84 & \multirow[t]{2}{*}{0.0253} \\
\hline Rural & 71.80 & 69.81 & 65.16 & \\
\hline \multicolumn{5}{|l|}{ Religion } \\
\hline Muslim & 13.50 & 57.24 & 64.13 & \multirow[t]{2}{*}{$<0.0001$} \\
\hline Traditional/Christian/Catholic/Other & 86.50 & 42.77 & 35.87 & \\
\hline \multicolumn{5}{|l|}{ Region } \\
\hline North Central & 14.85 & 14.44 & 14.62 & \multirow[t]{4}{*}{$<0.0001$} \\
\hline North East & 23.07 & 16.13 & 17.47 & \\
\hline North West & 36.89 & 32.04 & 38.41 & \\
\hline Southern regions & 25.19 & 37.39 & 29.50 & \\
\hline \multicolumn{5}{|l|}{ Education } \\
\hline None & 53.54 & 47.7I & 50.57 & 0.0003 \\
\hline Primary & 22.95 & 22.20 & 18.84 & \\
\hline Secondary & 19.83 & 24.07 & 24.21 & \\
\hline Higher & 3.67 & 6.02 & 6.37 & \\
\hline Wealth quintile & & & & \\
\hline I (poorest) & 22.29 & 23.72 & 24.34 & 0.9442 \\
\hline 2 & 21.91 & 22.44 & 22.81 & \\
\hline 3 & 20.95 & 18.52 & $|8.2|$ & \\
\hline 4 & 18.27 & 17.55 & 17.30 & \\
\hline 5 & 16.58 & 17.77 & 17.34 & \\
\hline Currently employed & & & & \\
\hline Yes & 63.64 & 63.78 & 64.47 & 0.4184 \\
\hline No & 36.36 & 36.22 & 35.53 & \\
\hline Attitudes toward intimate physical partr & & & & \\
\hline Permissible in some circumstances & 71.13 & 49.64 & 38.74 & $<0.000$ I \\
\hline Never & 28.87 & 50.36 & 61.26 & \\
\hline Women involved in health care decision & & & & \\
\hline Yes & 20.05 & 41.54 & 35.78 & $<0.000 \mathrm{I}$ \\
\hline No (ref) & 79.95 & 58.46 & 64.22 & \\
\hline Number of antenatal care visits (contins & ), during mo & ancy & & \\
\hline 0 & 39.45 & 40.88 & 36.21 & $<0.0001$ \\
\hline 1 & 2.72 & 1.53 & 1.78 & \\
\hline 2 & 4.57 & 3.18 & 3.75 & \\
\hline 3 & 6.47 & 5.56 & 7.00 & \\
\hline 4 & 5.77 & 6.47 & 8.28 & \\
\hline $5+$ & 41.02 & 42.38 & 42.98 & \\
\hline Given or bought iron supplements durir & regnancy & & & \\
\hline Yes & 58.37 & 54.84 & 62.98 & $<0.000$ I \\
\hline No & 41.63 & 45.16 & 37.02 & \\
\hline Woman stated that getting permission $t$ & re was a big & getting med & self & \\
\hline Yes & 11.14 & 16.43 & 12.22 & 0.0003 \\
\hline No & 88.86 & 83.57 & 87.78 & \\
\hline Woman stated that the distance to a he & big problen & medical care & & \\
\hline Yes & 26.05 & 40.05 & 31.77 & $<0.000$ I \\
\hline No & 73.95 & 59.95 & 68.23 & \\
\hline
\end{tabular}

Notes: Total sample size was 38,546: in 2003 the sample size was 3,410; in 2008 the sample size was 16,728; in 2013 the sample size was 18,408. aRespondent was living in a household with cowives. 'Intimate partner violence is acceptable under any of the following conditions: wife goes out without telling her husband; wife neglects her children; wife argues with her husband; wife refuses to have sex with her husband, or she burns food. 'Respondent is involved in decisions regarding her health, either alone, with a spouse, or with another person.

Abbreviation: ref, reference group. 


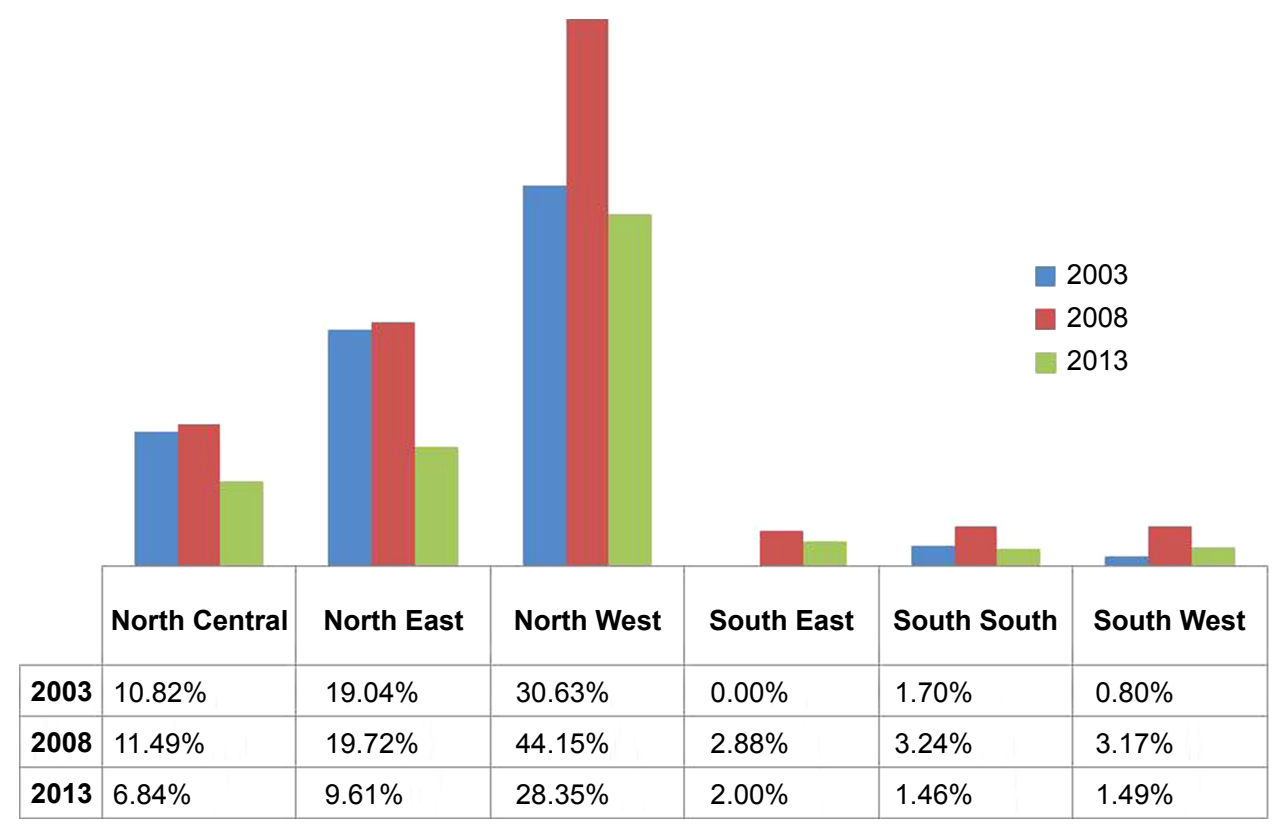

Figure 2 Percentage of married Nigerian women (who had given birth in the five years preceding the survey) who gave birth with no one present, by region.

Women who had not accessed any antenatal care were six times more likely to have given birth alone, relative to those who had five or more visits, $\mathrm{OR}=6.73 ;(5.83,7.76)$, and women who had taken iron supplements during pregnancy were significantly less likely to have given birth alone $\mathrm{OR}=0.27 ;(0.24,0.31)$. Women who stated that getting permission to seek health care was a big problem were significantly more likely to give birth alone, $\mathrm{OR}=1.80 ;(1.59,2.04)$, as were those who noted that distance to the facility was a big problem when seeking care, $\mathrm{OR}=1.47 ;(1.30,1.66)$. As all of the independent variables were predictive of a woman giving birth with NOP in the unadjusted analyses, all of them were included in the final model.

Table 3 Trends in the percentage of married women, who had given birth in the 5 years preceding survey, who gave birth alone

\begin{tabular}{|c|c|c|c|c|c|}
\hline State & 2003 (\%) & 2008 (\%) & $2013(\%)$ & $\begin{array}{l}\text { Percentage point difference } \\
\text { between } 2003 \text { and } 2013\end{array}$ & $\begin{array}{l}\text { Rate of decline } \\
\text { over } 10 \text { years (\%) }\end{array}$ \\
\hline Sokoto & 27 & 25 & 0 & 0.26 & 99 \\
\hline Zamfara & 32 & 61 & 46 & -0.15 & -46 \\
\hline Katsina & 24 & 62 & 27 & -0.03 & -11 \\
\hline Jigawa & $4 I$ & 28 & 22 & 0.19 & 46 \\
\hline Yobe & 16 & 18 & 0 & 0.16 & 99 \\
\hline Borno & 7 & 9 & 3 & 0.04 & 58 \\
\hline Adamawa & 3 & 18 & 7 & -0.05 & -194 \\
\hline Gombe & 14 & 14 & 16 & -0.02 & -17 \\
\hline Bauchi & 26 & 36 & 21 & 0.05 & 20 \\
\hline Kano & 38 & 59 & 41 & -0.02 & -6 \\
\hline Kaduna & 29 & 6 & 16 & 0.14 & 47 \\
\hline Kebbi & 20 & 55 & 27 & -0.07 & -36 \\
\hline Niger & 23 & 19 & 6 & 0.16 & 71 \\
\hline FCT - Abuja & 19 & 5 & 4 & 0.14 & 77 \\
\hline Nasarawa & 9 & 9 & 12 & -0.03 & -37 \\
\hline Plateau & 5 & 5 & 14 & -0.08 & -153 \\
\hline Taraba & 35 & 11 & 10 & 0.25 & 72 \\
\hline Benue & 5 & 2 & 7 & -0.02 & -40 \\
\hline Kogi & 7 & 6 & I & 0.06 & 92 \\
\hline Kwara & 6 & 30 & I & 0.05 & 83 \\
\hline
\end{tabular}

Note: Data in bold show significance is expressed by the sheer magnitude of the change. Abbreviation: FCT, Federal Capital Territory. 
Table 4 Unadjusted odds ratios, by survey year, predicting married Nigerian women's most recent birth (among women who had given birth in the 5 years preceding the survey) occurring with no one present ${ }^{\mathrm{a}}$

\begin{tabular}{|c|c|c|}
\hline Variable & Unadjusted odds ratio & $95 \%$ confidence limits \\
\hline \multicolumn{3}{|l|}{ Year } \\
\hline 2003 & 1.30 & $1.04,1.64$ \\
\hline 2008 & 1.54 & $1.31,1.82$ \\
\hline \multicolumn{3}{|l|}{2013 (ref) } \\
\hline \multicolumn{3}{|l|}{ Age (years) } \\
\hline $15-24$ & 0.67 & $0.61,0.73$ \\
\hline $25-34$ & 0.73 & $0.68,0.79$ \\
\hline \multicolumn{3}{|l|}{$35+($ ref) } \\
\hline \multicolumn{3}{|l|}{ Number of births } \\
\hline I & 0.28 & $0.25,0.32$ \\
\hline 2 & 0.50 & $0.46,0.55$ \\
\hline 3 & 0.58 & $0.52,0.63$ \\
\hline \multicolumn{3}{|l|}{$4+($ ref) } \\
\hline \multicolumn{3}{|l|}{ Cowife $^{b}$} \\
\hline Yes & 2.13 & $1.96,2.31$ \\
\hline \multicolumn{3}{|l|}{ No (ref) } \\
\hline \multicolumn{3}{|l|}{ Residence } \\
\hline Urban & 0.32 & $0.26,0.39$ \\
\hline \multicolumn{3}{|l|}{ Rural (ref) } \\
\hline \multicolumn{3}{|l|}{ Religion } \\
\hline Muslim & 4.36 & $3.73,5.09$ \\
\hline \multicolumn{3}{|c|}{ Traditional/Christian/Catholic/Other (ref) } \\
\hline \multicolumn{3}{|c|}{ Region } \\
\hline North Central & 4.27 & $3.25,5.60$ \\
\hline North East & 7.29 & $5.62,9.47$ \\
\hline North West & 22.34 & $17.72,28.15$ \\
\hline \multicolumn{3}{|l|}{ Southern regions (ref) } \\
\hline \multicolumn{3}{|l|}{ Education } \\
\hline \multicolumn{3}{|l|}{ None (ref) } \\
\hline Primary & 0.31 & $0.27,0.35$ \\
\hline Secondary & 0.10 & $0.08,0.12$ \\
\hline Higher & 0.02 & $0.01,0.04$ \\
\hline Wealth quintile & & \\
\hline I (poorest) & $17.6 \mid$ & $13.20,23.49$ \\
\hline 2 & 12.42 & $9.36,16.48$ \\
\hline 3 & 6.87 & $5.20,9.07$ \\
\hline 4 & 3.30 & $2.52,4.33$ \\
\hline 5 (ref) & & \\
\hline Currently employed & & \\
\hline Yes & 0.70 & $0.64,0.78$ \\
\hline No (ref) & & \\
\hline Attitudes toward intimate physical pa & & \\
\hline Permissible in some circumstances & 1.40 & $1.26,1.57$ \\
\hline Never (ref) & & \\
\hline Women involved in health care decisi & & \\
\hline Yes & 0.28 & $0.25,0.32$ \\
\hline No (ref) & & \\
\hline Number of antenatal care visits, durin & & \\
\hline 0 & 6.73 & $5.83,7.76$ \\
\hline I & 2.79 & $2.14,3.65$ \\
\hline 2 & 2.83 & $2.29,3.50$ \\
\hline 3 & 2.35 & $1.97,2.80$ \\
\hline 4 & 2.02 & I.7I, 2.38 \\
\hline $5+($ ref) & & \\
\hline Given or bought iron supplements du & & \\
\hline Yes & 0.27 & $0.24,0.31$ \\
\hline No (ref) & & \\
\hline Woman stated that getting permissior & oblem, when getting medica & \\
\hline Yes & 1.80 & $1.59,2.04$ \\
\hline No & & \\
\hline Woman stated that the distance to a & when getting medical care $\mathrm{fc}$ & \\
\hline Yes & 1.47 & $1.30,1.66$ \\
\hline No & & \\
\hline
\end{tabular}

Notes: a"Births alone" indicates that the most recent birth was assisted by no one. $n=38,546$. $C=0.82$. 'Respondent was living in a household with cowives. Intimate partner violence is acceptable under any of the following conditions: wife goes out without telling her husband; wife neglects her children; wife argues with her husband; wife refuses to have sex with her husband, or she burns food. ${ }^{~}$ Respondent is involved in decisions regarding her health, either alone, with a spouse, or with another person. Abbreviation: ref, reference group. 


\section{Adjusted results}

As shown in Table 5, significant declines were observed in the odds of women giving birth with NOP between 2003 and 2013. The independent effects of women's age, parity, religion, cowife status, wealth quintile, education, and region were statistically significant. Of these factors, region has the singular most important effect, with women from the North West roughly seven times more likely to deliver with NOP compared to women from the South, adjusted $\mathrm{OR}=6.78 ;(5.23,8.80)$. Even in the most liberal Northern zones (eg, North Central) women were more than twice as likely to deliver with NOP as compared with the South, adjusted $\mathrm{OR}=2.29 ;(1.77,2.96)$. The second most important factor after region is wealth status. Women in the lowest wealth quintile were three times more likely to deliver with NOP when compared with their wealthier counterparts in the topmost quintile, adjusted $\mathrm{OR}=3.10 ;(2.25,4.25)$, and any small improvements in economic security of the participants translated into significant gains in births with someone present. This analysis clearly shows that increased access to the health system reduces the probability of a woman giving birth alone; each additional antenatal care visit increased the odds of delivery with some attendance by $12 \%$, adjusted OR $=0.88 ;(0.85,0.91)$. At the individual level, adjusted results show that education and involvement in decision making about their own health resulted in fewer women delivering with NOP. Conversely, women's age, parity, religion, and cowife status increased women's exposure to the odds of delivering with NOP. One key observation from Table 5 is the strong effect of time, after controlling for other covariates. In other words, the declines in delivery with NOP overtime were bigger than what is accounted by compositional changes in the population. The adjusted model fit well $(C=0.82) .{ }^{19}$

Given that distance to a health facility is not a significant predictor in the adjusted model, we further explored the association between giving birth alone and facility based birth. Of the 6,162 women who gave birth alone in this sample, $99.3 \%(6,117)$ gave birth outside of a facility, indicating that the phenomena of women giving birth alone overwhelmingly occur outside of the health system. We assumed that the sheer absence of a health facility with delivery services would be associated with increased levels of deliveries with NOP. The data revealed that in 2013, the percentage of women who delivered in any facility was $11.5 \%$ in the North West, $19.6 \%$ in the North East, and roughly $46 \%$ in North Central states. These proportions were largely unchanged between 2003 and 2013, and they are inversely related to NOP. These differences point to the fact that women residing in states where distance to facilities is a barrier are more likely to give birth with NOP. For example, the North West, with the lowest utilization of facility based care, had the highest prevalence of NOP. This could be indicative of fewer facilities in this region or of women bypassing available services because they are not acceptable, or could be indicative of the dearth of available services in this region (Table 6). Over time, there appears to be marginal increase in access to public facilities and small declines in the utilization of private facilities throughout Nigeria (Table 6). Although inconclusive, barring cultural factors that limit facility-based care, it is highly plausible that lower access to facilities in some regions may directly feed into the higher levels of deliveries with NOP in these states.

\section{Discussion}

This study confirmed the findings reported earlier by Faphohunda and Orobaton, clearly showing that women residing in the Northern regions of Nigeria are significantly more likely to give birth with NOP, relative to women residing in the Southern states. ${ }^{8,13}$ Interventions must target women and families in these states and increase their access to skilled delivery.

The role of private facilities should be explored in the context of public failures to provide adequate and acceptable access to health facilities. If governments are unable to make public investments to keep pace with the growth of facilities in the public health sector, then the use of incentives to promote the establishment of private facilities, a form of public-private partnerships, could be important in increasing access.

Another factor that needs to be addressed is the access to, utilization of, and quality of antenatal care services. Although we used the percentage of women who used iron supplements as a proxy, this did not show a significant effect in the adjusted model, probably because many women acquire iron through private vendors and not through the health system or antenatal care. Nonetheless, we do see that areas where there has been the least increase in iron supplementation also have the highest prevalence of women giving birth with NOP (Table 7).

As mentioned earlier, several States in the northern region of Nigeria, including the Federal Capital Territory, Kogi, Kwara, Niger, Sokoto, Taraba, and Yobe States, recorded sharp decline in delivery with NOP levels over the periods studied (Table 2). Although the determinants of this decline require systematic documentation, illustrative data from Sokoto State indicate that diffusion of ideas supportive of small family size and maternal health care could have played 
Table 5 Adjusted odds ratios, by survey year, predicting married Nigerian women's most recent birth (among women who had given birth in the 5 years preceding the survey) occurring with no one present ${ }^{\mathrm{a}}$

\begin{tabular}{|c|c|c|}
\hline Variable & Adjusted odds ratio & $\mathbf{9 5 \%}$ confidence limits \\
\hline \multicolumn{3}{|l|}{ Year } \\
\hline 2003 & 2.19 & I.72, 2.80 \\
\hline 2008 & 2.05 & $1.76,2.38$ \\
\hline \multicolumn{3}{|l|}{2013 (ref) } \\
\hline \multicolumn{3}{|l|}{ Age (years) } \\
\hline $15-24$ & 0.81 & $0.70,0.92$ \\
\hline $25-34$ & 0.85 & $0.78,0.93$ \\
\hline \multicolumn{3}{|l|}{$35+($ ref $)$} \\
\hline \multicolumn{3}{|l|}{ Number of births } \\
\hline 1 & 0.34 & $0.29,0.40$ \\
\hline 2 & 0.70 & $0.61,0.79$ \\
\hline 3 & 0.77 & $0.69,0.86$ \\
\hline \multicolumn{3}{|l|}{$4+$ (ref) } \\
\hline \multicolumn{3}{|l|}{ Cowife $^{b}$} \\
\hline Yes & 1.15 & $1.05,1.25$ \\
\hline \multicolumn{3}{|l|}{ No (ref) } \\
\hline \multicolumn{3}{|l|}{ Residence } \\
\hline Urban & 1.03 & $0.84,1.26$ \\
\hline \multicolumn{3}{|l|}{ Rural (ref) } \\
\hline \multicolumn{3}{|l|}{ Religion } \\
\hline Muslim & 1.60 & $1.34,1.91$ \\
\hline \multicolumn{3}{|l|}{ Traditional/Christian/Catholic/Other (ref) } \\
\hline \multicolumn{3}{|l|}{ Region } \\
\hline North Central & 2.29 & I.77, 2.96 \\
\hline North East & 2.24 & $1.70,2.94$ \\
\hline North West & 6.78 & $5.23,8.80$ \\
\hline \multicolumn{3}{|l|}{ Southern regions (ref) } \\
\hline \multicolumn{3}{|l|}{ Education } \\
\hline \multicolumn{3}{|l|}{ None (ref) } \\
\hline Primary & 0.24 & $0.14,0.40$ \\
\hline Secondary & 0.66 & $0.54,0.80$ \\
\hline Higher & 0.24 & $0.14,0.40$ \\
\hline \multicolumn{3}{|l|}{ Wealth quintile } \\
\hline I (poorest) & 3.10 & $2.25,4.25$ \\
\hline 2 & 2.52 & $1.86,3.40$ \\
\hline 3 & 2.20 & $1.65,2.94$ \\
\hline 4 & 1.57 & $1.19,2.07$ \\
\hline \multicolumn{3}{|l|}{5 (ref) } \\
\hline \multicolumn{3}{|l|}{ Currently employed } \\
\hline Yes & 1.16 & $1.04,1.30$ \\
\hline No (ref) & & \\
\hline Attitudes toward intimate physical partner violence ${ }^{c}$ & & \\
\hline Permissible in some circumstances & 0.91 & $0.8 \mathrm{I}, \mathrm{I} .02$ \\
\hline Never (ref) & & \\
\hline Women involved in health care decisions ${ }^{d}$ & & \\
\hline Yes & 0.75 & $0.66,0.86$ \\
\hline No (ref) & & \\
\hline Number of antenatal care visits, during most recent pregnancy & 0.88 & $0.85,0.91$ \\
\hline Given or bought iron supplements during most recent pregnan & & \\
\hline Yes & 1.05 & $0.91,1.20$ \\
\hline No (ref) & & \\
\hline Woman stated that getting permission to seek health care was & en getting medical care fo & \\
\hline Yes & 0.95 & $0.82,1.10$ \\
\hline No & & \\
\hline Woman stated that the distance to a health facility was a big pr & g medical care for hersel & \\
\hline Yes & 0.93 & $0.82,1.06$ \\
\hline No & & \\
\hline
\end{tabular}

Notes: "Births alone" indicates that the most recent birth was assisted by no one. $\mathrm{n}=38,546$; all analyses were adjusted for survey design, sampling errors, and uneven weights using the SAS v. 9.2 survey procedures. $C=0.82$. ${ }^{\circ}$ Respondent was living in a household with cowives. Intimate partner violence is acceptable under any of the following conditions: wife goes out without telling her husband; wife neglects her children; wife argues with her husband; wife refuses to have sex with her husband, or she burns food. ${ }^{~}$ Respondent is involved in decisions regarding her health, either alone, with a spouse, or with another person.

Abbreviation: ref, reference group. 
Table 6 Distribution of where most recent birth occurred by region, in married women with at least one birth in the years preceding the survey

\begin{tabular}{|c|c|c|c|c|}
\hline Variable & 2003 (\%) & 2008 (\%) & $2013(\%)$ & $\begin{array}{l}\text { Percentage point difference } \\
\text { between } 2003 \text { and } 2013\end{array}$ \\
\hline \multicolumn{5}{|l|}{ North Central } \\
\hline Non-facility & 53.78 & 58.00 & 53.00 & -0.78 \\
\hline Public & 27.38 & 27.75 & 31.45 & 4.07 \\
\hline Private & 18.84 & 13.97 & 15.50 & -3.34 \\
\hline \multicolumn{5}{|l|}{ North East } \\
\hline Non-facility & 81.67 & 86.51 & 79.90 & -1.77 \\
\hline Public & 15.66 & $|2.6|$ & 18.83 & 3.17 \\
\hline Private & 2.78 & 0.89 & 1.27 & $-|.5|$ \\
\hline \multicolumn{5}{|l|}{ North West } \\
\hline Non-facility & 89.29 & 91.02 & 87.52 & -1.77 \\
\hline Public & 9.08 & 8.09 & 11.97 & 2.89 \\
\hline Private & 1.63 & 0.90 & 0.52 & -1.11 \\
\hline \multicolumn{5}{|c|}{ Southern regions } \\
\hline Non-facility & 32.03 & 33.40 & 28.16 & -3.87 \\
\hline Public & 29.55 & 32.88 & 36.27 & 6.72 \\
\hline Private & 38.41 & 37.72 & 34.57 & -3.84 \\
\hline
\end{tabular}

a major role. For example, since July 2012, NOP has been repeatedly debated in state policy and legislative circles with religious leaders and district heads throughout the Sokoto state. This discussion was backed by real programmatic developments in maternal health. For example, during the same period, USAID Targeted States High Impact Project, a USAID-supported technical assistance project dedicated to increasing the use of quality maternal, newborn, and child health services, supported Sokoto State and trained 2,440 community-based health volunteers (CBHV) spread across all 244 political wards in the state to distribute misoprostol and chlorhexidine gel $4 \%$ as per the project's report (USAID, unpublished data, 2009). Included in the training, CBHV were taught to counsel mothers on the importance of skilled delivery assistance. Although the actual community-based distribution of commodities did not start until April 2013, after the NDHS survey had commenced, there were deliberate campaigns reaching community leaders and households about the riskiness of unskilled attendance and the implications it had on maternal and newborn health. This new awareness could have helped to sharply reduce the desirability of risky delivery practices in the region, culminating in the drop in prevalence of delivery with NOP, which was later observed in the 2013 NDHS. Surprisingly, facility-based deliveries remained unchanged throughout the 10 years. That is, in none of the States observed did the sharp decline in NOP translate to a higher usage of skilled delivery assistance, implying that women, although less likely to give birth alone, are still not accessing skilled care. This underscores the point that the eradication of NOP is fully meaningful only when women elect to use skilled delivery assistance. This too must be the end goal of NOP eradication.

As Fapohunda and Orobaton have recommended in an earlier analysis, ${ }^{13}$ possible interventions to mitigate the effects of poverty could include the use of conditional cash transfers to increase women's ability to overcome finance-related barriers in the use of formal health services. Additionally, the authors also clearly articulate other factors that need to be addressed to improve women's economic security, including access to higher education and employment. ${ }^{13}$

Urban residence was not a significant predictor of women's odds to give birth alone. This counterintuitive finding may be

Table 7 Percentage of women who took iron tablets or syrup in zones, in 2003-2013, and prevalence of women giving birth with NOP, prevalence by region

\begin{tabular}{llllll}
\hline Region & $\mathbf{2 0 0 3}$ & $\mathbf{2 0 0 8}$ & $\mathbf{2 0 1 3}$ & $\begin{array}{l}\text { Percent difference between } \\
\text { 2003 and 2013 (\%) }\end{array}$ & NOP in 2013 (\%) \\
\hline North West & 40.6 & 30.6 & 43.9 & 8 & 28 \\
North East & 54.4 & 46 & 61.7 & 13 & 10 \\
North Central & 58.7 & 50.3 & 71.4 & 22 & 7 \\
\hline
\end{tabular}

Abbreviation: NOP, no one present. 
explained by the increasing urban inequalities within Nigeria. As Matthews et $\mathrm{al}^{20}$ articulated, Nigeria is a country with large urban inequalities, (a substantial population which is rich and has the advantage of access to maternal and newborn care) and, in parallel, large rural inequalities (in rural areas where rural rich have distinct advantages in access to services). The null finding of urban residence and the clear indication that poverty is a strong predictor of NOP support this finding.

One factor that would reduce the risk of women giving birth with NOP, would be the scale-up of modern long-acting contraceptive methods for family planning. Recent findings have shown that $16 \%$ of women in Nigeria have an unmet need for contraception. ${ }^{21}$ Ensuring that women, who have articulated a demand for contraception, are able to access affordable and acceptable methods would be a key intervention in improving maternal health outcomes.

There seems to be two factors that influence women's access to skilled care: on the supply side, a health system that does not ensure equitable access to women in all regions of the country and, on the demand side, women's decision/ ability to utilize available services. While these analyses did not control for the distribution of maternal health facilities and/or the distribution of skilled providers in Nigeria, the disproportionate burden of women giving birth with NOP in the North may be the direct result of fewer accessible maternal health resources in those regions compounded by sociocultural and economic issues impacting care seeking behavior. More research is needed to understand the contribution of both supply and demand side issues that impact women's choice and ability to utilize quality maternal health services in different regions of Nigeria.

\section{Study limitations}

A key weakness of this paper is the potential underestimation of the prevalence of delivery with NOP in the populations studied. The data from the Nigerian Demographic and Health Survey is collected through self-report from women who survived child birth. Data on women who died during childbirth were not collected. The levels and impact of delivery with NOP may have been much greater than documented in this paper, if we had access to complete data.

\section{Conclusion}

Our analyses show that there have been declines in the prevalence of women who have given birth with NOP in Nigeria. Despite this, there is significant room for improvement and clear geographical and socioeconomic vulnerabilities. These analyses have confirmed earlier findings that women in the
North of Nigeria disproportionally bear the burden of giving birth with NOP, and that poverty, low educational levels, and a lack of decision-making power exacerbate the risk of a woman giving birth with NOP.$^{8,13}$ Our findings are further affirmation of promising levers that could be exploited to eradicate the practice. As a matter of urgent national policy, women who deliver with NOP should constitute a top priority for all governments in Nigeria, especially in North West and North East Nigeria. Interventions that target older and multiparous women engaging in NOP practices remain very critical for successful eradication of the practice. In addition, interventions such as conditional (or unconditional) cash transfers, or incentive schemes that increase the likelihood that women in the lowest income quintiles will attend a health facility for delivery services remain quite relevant for program success. The use of incentives for public-private partnerships should be considered in the North West of the country. Contact with the health system during pregnancy through antenatal care visits was also found to significantly reduce the odds of women giving birth with NOP. Increasing access to and utilization of quality ANC services, and ensuring all women have full access and choice to modern contraceptive methods are key mechanisms to help reduce the prevalence of women giving birth alone. Finally, we call for more studies, particularly qualitative studies, to assist policy makers design the most sensible and acceptable interventions.

Ensuring that all women in Nigeria have access to and utilize available high quality maternal health services is the only way for the country to ensure that no woman dies of preventable maternal causes or suffers a preventable injury during childbirth. In order to do so, there must not only be system level investments to make high quality services available and affordable, but also interventions to ensure that women (and men) find these services acceptable, and have the agency to utilize them.

\section{Disclosure}

This work was supported by the Maternal Health Task Force at the Harvard School of Public Health. The authors report no conflicts of interest in this work.

\section{References}

1. World Health Organization. Trends in Maternal Mortality: 1990 to 2013. Estimates by WHO, UNICEF, UNFPA, The World Bank and The United Nations Population Division. Geneva, Switzerland: World Health Organization; 2014.

2. Population Division, Department of Economic and Social Affairs, United Nations. World Population Prospects: The 2012 Revision, Highlights and Advance Tables. Working Paper No. ESA/P/WP228. New York, NY: United Nations; 2013. 
3. National Population Commission (NPC) [Nigeria] and ICF International. Nigeria Demographic and Health Survey 2013. Abuja, Nigeria, and Rockville, MD, USA: NPC and ICF International; 2014.

4. Graham WJ, Bell JS, Bullough CHW. Can skilled attendance at delivery reduce maternal mortality in developing countries? In: De Brouwere V, Van Lerberghe W, editors. Safe Motherhood Strategies: A Review of the Evidence. Antwerp, Belgium: ITG Press; 2001:97-130.

5. Bhutta ZA, Chopra M, Axelson H, et al. Countdown to 2015 decade report (2000-2010): taking stock of maternal, newborn, and child survival. Lancet. 2010;375(9730):2032-2044.

6. Doctor HV, Olatunji A, Findley SE, Afenyadu GY, Abdulwahab A, Jumare A. Maternal mortality in northern Nigeria: findings of a health and demographic surveillance system in Zamfara State, Nigeria. Trop Doct. 2012;42(3):140-143.

7. Campbell OM, Graham WJ. Strategies for reducing maternal mortality: getting on with what works. Lancet. 2006;368(9543):1284-1299.

8. Fapohunda BM, Orobaton NG. When women deliver with no one present in Nigeria: who, what, where and so what? PLoS One. 2013;8(7):e69569.

9. The DHS Program. Demographic and Health Surveys; USAID, ICF International. Available from: http://www.measuredhs.com [homepage on the Internet]. Accessed May 15, 2014.

10. National Population Commission, Nigeria. Ensuring global population competitiveness. Available from: http://www.population.gov.ng/index. $\mathrm{php} /$ state-population [homepage on the Internet]. Accessed February 17, 2015.

11. Ononokpono DN, Odimegwu CO. Determinants of maternal health care utilization in Nigeria: a multilevel approach. Pan Afr Med J. 2014; (17 Suppl 1):2.

12. Corroon M, Speizer IS, Fotso JC, et al. The role of gender empowerment on reproductive health outcomes in urban Nigeria. Matern Child Health J. 2014;18(1):307-315.
13. Fapohunda B, Orobaton N. Factors influencing the selection of delivery with no one present in Northern Nigeria: implications for policy and programs. Int J Women's Health. 2014;6:171-183.

14. Parkhurst JO, Rahman SA, Ssengooba F. Overcoming access barriers for facility-based delivery in low-income settings: insights from Bangladesh and Uganda. J Health Popul Nutr. 2006;24(4):438-445.

15. Singh K, Bloom S, Haney E, Olorunsaiye C, Brodish P. Gender equality and childbirth in a health facility: Nigeria and MDG5. Afr J Reprod Health. 2012;16(3):123-129.

16. Babalola S, Fatusi A. Determinants of use of maternal health services in Nigeria - looking beyond individual and household factors. $B M C$ Pregnancy Childbirth. 2009;9:43.

17. Faye A, Niane M, Ba I. Home birth in women who have given birth at least once in a health facility: contributory factors in a developing country. Acta Obstet Gynecol Scand. 2011;90(11):1239-1243.

18. Deaton AS. The Analysis of Household Surveys: A Microeconometric Approach to Development Policy. Baltimore, MD: Johns Hopkins University Press; 1997.

19. Hosmer D, Lemeshow S. Applied Logistic Regression. 2nd ed. New York, NY: John Wiley \& Sons; 2000.

20. Matthews Z, Channon A, Neal S, Osrin D, Madise N, Stones W. Examining the "urban advantage" in maternal health care in developing countries. PLoS Med. 2010;7(9):e1000327.

21. Austin A. Unmet contraceptive need among married Nigerian women: an examination of trends and drivers. Contraception. 2014;91(1):31-38.
International Journal of Women's Health

\section{Publish your work in this journal}

The International Journal of Women's Health is an international, peerreviewed open-access journal publishing original research, reports, editorials, reviews and commentaries on all aspects of women's healthcare including gynecology, obstetrics, and breast cancer. The manuscript management system is completely online and includes

\section{Dovepress}

a very quick and fair peer-review system, which is all easy to use. Visit http://www.dovepress.com/testimonials.php to read real quotes from published authors. 